\title{
STRATEGI PENGENDALIAN KUALITAS PADA PROSES PENANGANAN RAJUNGAN MENGGUNAKAN METODE ANALYTICAL HIERARCHY PROCESS
}

\author{
Anita Wulandari ${ }^{1}$, Mahrus $\mathrm{Ali}^{2}$, Veronika Nugraheni $\mathrm{SL}^{3}$ \\ ${ }^{1}$ Politeknik Surabaya \\ ${ }^{2}$ Universitas Merdeka Surabaya \\ ${ }^{3}$ Universitas Dr. Soetomo Surabaya \\ Email : wulandari.nt@gmail.com
}

\begin{abstract}
Abstrak
Rajungan termasuk salah satu hasil perikanan yang umumnya bersifat perishable food (mudah rusak/busuk), tentunya setelah pengupasan rajungan kemungkinan besar terdapat pada penanganan yang kurang baik sehingga kualitas kurang baik. Untuk itu dibutuhkan strategi pengendalian kualitas yang tepat untuk mengaplikasikan yaitu dengan metode AHP (Analytical Hierarchy Process). Sebagai responden dipilih 3 orang pengambilan keputusan di perusahaan PT. Tonga Tiur Putra. Dari hasil Analisis bahwa faktor yang mempengaruhi kualitas daging rajungan terdapat pada transportasi, dan alternative yang tepat untuk mengendalikan kualitas daging rajungan dengan cara pengadaan dan pelatihan SDM.
\end{abstract}

Kata Kunci : Kepiting, SDM, AHP

\begin{abstract}
Including one small crab fishery are generally perishable food (easily broken/ rotten), of course, after stripping the small crab is most likely present in the less well handling so the quality is less good. That requires proper quality control strategy to apply is by AHP (Analytical Hierarchy Process). As the respondents selected three people making decisions in the company of PT. Tonga Tiur Putra. From the results of analysis that the factors that affect the quality of small crab meat found in transportation, and appropriate alternative for small crab meat quality control by means of procurement and human resource training.
\end{abstract}

KeyWord : Crab, Human Resource, AHP

\section{PENDAHULUAN}

\section{Latar Belakang}

Indonesia menyimpan sumber daya kekayaan laut yang potensial. Sudah lebih dari 30 tahun terakhir dunia mengenal perairan Indonesia sebagai kawasan tangkapan ikan yang sangat potensial di dunia. Mengingat potensi sumber daya laut Indonesia yang sangat besar, menjadi sangat penting dikembangkannya industri pengolahan ikan di Indonesia. Salah satu Industri pengolahan ikan yang perlu dikembangkan adalah industri pengolahan daging rajungan. Potensi rajungan di Indonesia serta permintaan yang tinggi dari dalam maupun luar negeri mendukung industri ini untuk dikembangkan.

Salah satu industri pengupasan daging rajungan adalah PT Tonga Tiur Putra. Perusahaan tersebut mempunyai masalah utama yang dihadapi adalah penanganan rajungan yang kurang standar sehingga mengalami kemerosotan harga dan mutu yang belum menjamin sampai ke perusahaan pengalengan. Hal ini disebabkan terbatasnya pengetahuan tenaga kerja mengenai kualitas dan pengawasan selama proses produksi.

PT. Tonga Tiur Putra tetap berusaha untuk dapat bertahan dan memiliki keinginan untuk mengembangkan usahanya. Agar suatu perusahaan dapat terus berkembang, maka dibutuh strategi pengendalian kualitas yang tepat dengan metode AHP (Analytical Hierarchy Process ). Metode AHP merupakan untuk pengambilan keputusan dalam menyelesaikan masalah-masalah dalam hal perencanaan, penentuan alternatif, penyusunan prioritas, pemilihan kebijaksanaan, alokasi sumber daya, penentuan kebutuhan, peramalan hasil, perencanaan sistem, pengukuran performansi, optimasi, dan pemecahan konflik (Saaty, 1994).

\section{METODE PENELITIAN}

Permasalahan yang timbul dalam mencapai tujuan yang telah ditetapkan diatas adalah bagaimana menyusun permasalahan menjadi suatu tatanan hirarki keputusan.

Pengumpulan data dilakukan dengan 4 cara yaitu wawancara, observasi, studi pustaka, dokumentasi perusahaan.

1. Wawancara

Dilakukan dengan tanya jawab pemilik perusahaan dan manajemen perusahaan untuk mendapatkan informasi mengenai penanganan rajungan untuk mengendalikan kualitas. 
2. Observasi

Yaitu pengumpulan dengan mengidentifikasi faktor, tujuan, dan strategi yang tepat.

3. Studi pustaka

Studi kepustakaan dilakukan dengan tujuan untuk memperoleh data rujukan teoritis yang terkait dengan penelitian

4. Dokumen perusahaan

Dokumen perusahaan yang diperlukan meliputi data gambaran umum perusahaan (sejarah, aspek

\section{Pengolahan Data}

produksi, visi dan misi, aspek pemasaran, aspek organisasi).

1. Pengolahan dilakukan dengan menggunakan AHP. Tahapan-tahapan dalam metode AHP adalah sebagai berikut :

a) Menyusun Heirarchy

Sesuai dengan permasalahan yang didapat tentang strategi pengendalian yaitu faktor pengendalian kualitas terhadap proses pananganan rajungan, level I berisi variabel tranportasi, bahan baku, SDM, dan teknologi proses, level II berisi parameter tujuan dari variabel-variabel. Sedangkan level III berisi strategi pengendalian kualitas yaitu pengadaan pelatihan SDM, Penerapan GMP, penerapan sistem pengendalian kualitas, pengembangan sistem informasi, penerapan teknologi.

b) Menyusun matriks pendapat individu dari masing-masing responden.

c) Menyusun matriks pendapat gabungan $(\mathrm{G})$ dari masing-masing responden. Elemen-elemen matriksnya $\left(\mathrm{g}_{i j}\right)$ berasal dari rata-rata geometrik elemen-elemen matriks pendapat individu (aij) yang rasio konsitensinya (RK) memenuhi persyaratan. Rata-rata geometri diperoleh dengan rumus :

$$
g_{i j}=\sqrt[m]{\prod_{k=1}^{m} a_{i j(k)}}
$$

d) Bobot kriteria kompetensi (VP) diperoleh dengan membagi total nilai normalisasi tiap kriteria dengan total nilai normalisasi seluruh kriteria.

Nilai normalisasi $(\mathrm{VP})=$

$$
\frac{g_{i j}}{\sum_{i=1}^{n} g_{i j}}
$$

e) Nilai Rasio Konsitensi (RK) merupakan tolok ukur konsitensi hasil komparasi berpasangan.

$$
(R K)=\frac{I K}{A I}
$$

Pengujian ini dilakukan terhadap kriteria. Jika rasio inkonsisten lebih atau lebih dari 0,1 maka nilai tersebut tidak konsisten.

dimana aij nilai skala perbandingan antara kriteria ke i dan ke $j$.

f) Menentukan nilai $\lambda$ maks:

$$
\sum(\text { jumlah kolom } k e-j \quad x \quad \text { Vpi untuk } i=j)
$$

g) Menentukan Indeks Konsistensi (IK) dengan rumus :

$$
(\mathrm{IK})=\frac{\lambda \text { maks }-\mathrm{n}}{n-1}
$$

Indeks konsistensi (CI), matriks random dengan skala penilaian (1-9) beserta kebalikannya sebagai Indeks Random (RI).

Berdasarkan perhitungan Saaty dengan menggunakan 500 sampel, jika "judgement" numerik diambil secara acak dari skala $1 / 9,1 / 8, \ldots 1,2, \ldots, 9$ akan diperoleh rata-rata konsistensi untuk matriks dengan ukuran yang berbeda, sebagai berikut Tabel 1:

\begin{tabular}{|c|l|}
\hline Ordo Matriks & Indeks Random \\
\hline 1,2 & 0,00 \\
\hline 3 & 0,58 \\
\hline 4 & 0,90 \\
\hline 5 & 1,12 \\
\hline
\end{tabular}




\begin{tabular}{|c|l|}
\hline 6 & 1,24 \\
\hline 7 & 1,32 \\
\hline 8 & 1,41 \\
\hline 9 & 1,45 \\
\hline 10 & 1,49 \\
\hline 11 & 1,51 \\
\hline 12 & 1,48 \\
\hline 13 & 1,56 \\
\hline 14 & 1,57 \\
\hline 15 & 1,59 \\
\hline
\end{tabular}

\section{PEMBAHASAN}

\section{Menentukan Faktor Pengendalian Kualitas di Perusahaan}

Penyebaran kuisioner sebanyak tiga responden, responden tersebut merupakan pemilik dan dua manajemen perusahaan PT Tonga Tiur Putra. Permasalahan yang terjadi di perusahaan diantaranya:

1. Bahan baku

Penanganan rajungan tidak sesuai dengan standar SOP, pemilihan bahan baku yang kurang teliti sehingga dapat mempengaruhi kualitas daging rajungan, Penangkapan dari nelayan penanganannya kurang tepat, Pencucian rajungan tidak sesuai dengan prosedur SOP, Tidak ada pelabelan selama pengemasan rajungan, Pada saat perebusan bahan baku, penyortiran, dan pengepakan tidak menggunakan perangkat seragam dan terutama pada saat pengupasan rajungan tidak menggunakan sarung tangan dan masker.

\section{SDM}

SDM merupakan salah satu aset penting bagi perusahaan karena maju mundurnya sebuah organisasi yang sangat bergantung pada kualitas manusia. Hal yang dapat mempengaruhi kualitas pada daging rajungan adalah pekerja karyawan tidak sesuai dengan SOP, dan karyawan menyepelekan kondisi kerja dengan berbicara yang tidak penting, hal ini dapat mempengaruhi proses produksi dan juga pada produk yang sering kesalahan pada pengupasan. Manusia merupakan sumber potensi pencemaran yang mudah terkontaminasi dengan produk, jika karyawan tidak di sanitasi dengan baik (Fakhri, 2007).

3. Transportasi

Tempat pengambilan bahan baku lokasinya jauh sehingga membutuhkan sarana dan prasarana untuk menjaga bahan baku dari berbagai faktor serta dapat menjaga kualitas rajungan. Perlakuan tersebut yang dapat menurunkan mutu hasil perikanan antara lain penyimpanan dan pengangkutan di kapal; pendaratan ikan di pelabuhan atau tempat-tempat pelelangan dan penjualan atau tempat pendaratan yang lainnya; penges-an (perlakuan dengan memberikan es) atau pendinginan dengan cara yang lain; penyiangan, misal pemotongan, pembuangan sisik, pembuangan isi perut dan penyayatan, pencucian, pengolahan, misalnya penggaraman, pemeraman, pengalengan; dan distribusi (Hadiwiyoto, 1992).

4. Teknologi

Untuk teknologi pada perusahaan ini hanya mengadalkan pada perusahaan pengalengan saja. Sehingga untuk perusahaan pengupasan rajungan kurangnya alat yang memadai, dan perusahan ini hanya menjaga mutu daging dengan cara pendinginan. Untuk dapat memecahkan masalah dibutuhkan tujuan untuk mencapai kemajuan usaha pengembangan, tentunya dibidang pengupasan, tujuannya yaitu :

1. Meningkatkan kualitas

2. Meningkatkan citra dan daya saing produk

3. Menigkatkan volume hasil

4. Memperlancar arus produk

Sedangkan untuk mendapatkan strategi pengendalian kualitas selama proses produksi menjaga kualitas sampai ke proses pengalengan maka strategi yang tepat yaitu :

1) Pelatihan dan pengembangan SDM

2) Penerapan GMP

3) Penerapan pengendalian kualitas bahan baku

4) Pengembangan informasi 
5) Penerapan teknologi

Maka dengan unsur-unsur tersebut dapat dibentuk struktur AHP yang dapat dilihat pada Gambar 1.

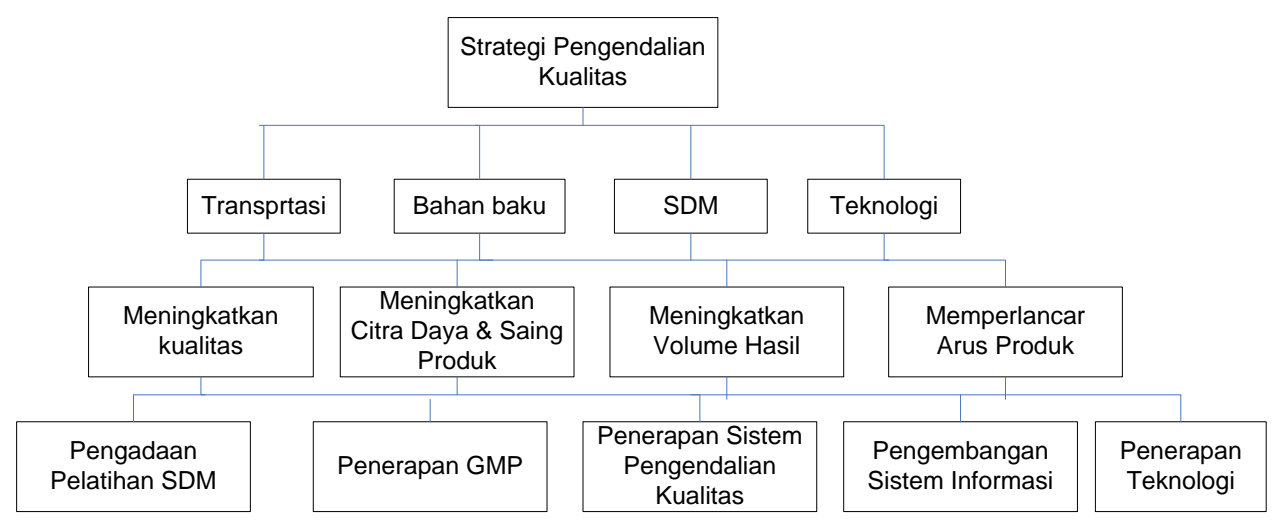

Gambar 1. Struktur Hirarky Strategi Pengendalian Kualitas

\section{Menentukan Tingkatan Faktor}

Berdasarkan tingkatan faktor yang terpilih maka akan dilakukan matrik perbandingan (pairwise comparation) antara elemen-elemennya, sehingga akan diperoleh bobot untuk masing-masing tingkatan faktor. Metode yang digunakan ialah comparative judgment atau skala banding secara berpasangan, prinsip ini berarti membuat penilaian tentang kepentingan relatif dua elemen pada suatu tingkat tertentu dalam kaitannya dengan tingkat di atasnya. Sesuai dengan perhitungan, bobot Prioritas tingkatan faktor dapat dilihat pada Tabel 2.

Sesuai dengan Tabel 2. Yang tertinggi pada faktor transportasi dengan bobot 0,517 atau $51,7 \%$ hal tersebut sangat berpengaruh pada proses produksi. Karena transportasi merupakan hal utama yang dibutuhkan untuk pengendalian kualitas pada proses penanganan rajungan.

Tabel 2. Bobot Prioritas pada tingkatan faktor

\begin{tabular}{|l|c|c|}
\hline \multicolumn{1}{|c|}{ Kriteria faktor } & Bobot & Prioritas \\
\hline Tranportasi & 0,517 & 1 \\
\hline Bahan baku & 0,245 & 2 \\
\hline SDM & 0,124 & 3 \\
\hline Teknologi & 0,114 & 4 \\
\hline
\end{tabular}

Sumber : Data primer

\section{Menentukan Tingkatan Tujuan}

Berdasarkan tujuan yang terpilih maka dilakukan matrik perbandingan (pairwise comparation) antara elemenelemennya, sehingga diperoleh bobot untuk masing-masing tingkatan tujuan dapat dilihat pada Tabel 3.

Tabel 3. Tingkatan Tujuan pada Strategi pengendalian kualitas

\begin{tabular}{|l|c|c|}
\hline \multicolumn{1}{|c|}{ Kriteria tujuan } & Bobot & prioritas \\
\hline Meningkatkan kualitas & 0,413 & 1 \\
\hline Meningkatkan citra daya dan saing produk & 0,257 & 2 \\
\hline Meningkatkan volume hasil & 0,146 & 3 \\
\hline Memperlancar arus penyaluran produk & 0,183 & 4 \\
\hline
\end{tabular}

\section{Sumber : Data Primer}

Pada Tabel 3. Tingkatan tujuan diatas sesuai dengan perhitungan pada setiap variabel faktor yang mencapai bobot tertinggi adalah meningkatkan kualitas dengan bobot $(0,431)$ pada transportasi, hal ini disebabkan perusahaan menginginkan kualitas yang terbaik untuk mencapai tujuan hasil akhir.

Untuk mencapai tujuan akhir dengan meningkatkan kualitas, didekati dengan nilai indeks mutu berdasarkan standar yang ditentukan oleh konsumen, dalam proses pemasaran, dan kualitas menjadi faktor penentu mencapai tujuan akhir (Rochman, dkk, 2007).

\section{Menentukan Tingkatan Strategi}

Berdasarkan tingkatan strategi yang sudah ditentukan perusahaan, dimana strategi pengendalian kualitas yang pertama dilakukan sesuai dengan perhitungan dengan metode AHP dapat dilihat pada Tabel 4. Sesuai dengan perhitungan dengan bobot yang tinggi dapat menentukan strategi pengendalian yang ada di pabrik pengupasan rajungan. 
Tabel 4. Bobot prioritas pada strategi

\begin{tabular}{|l|c|c|c|}
\hline \multicolumn{1}{|c|}{ Kriteria Strategi } & Bobot & Persentase & Prioritas \\
\hline Pengembangan dan pelatihan SDM & 0,303 & 30,3 & 1 \\
\hline Penerapan GMP & 0,226 & 22,6 & 2 \\
\hline Pengembangan informasi & 0,202 & 20,2 & 3 \\
\hline Penerapan sistem pengendalian bahan baku & 0,176 & 17,6 & 4 \\
\hline Penerapan teknologi & 0,137 & 13,7 & 5 \\
\hline
\end{tabular}

Sumber : Data Primer

Menurut Dwiprabowo (2001) menjelaskan bahwa dengan menentukan nilai prioritas yang lebih besar dengan metode AHP, dapat menentukan data sesuai dengan kondisi yang ada di lapang.

Strategi pengembangan dan pelatihan SDM merupakan prioritas yang utama untuk strategi pengendalian kualitas pada proses penanganan rajungan di PT Tonga Tiur Putra. Prioritas ini merupakan strategi yang tepat untuk mengendalikan kualitas pada proses penanganan rajungan. Karena dengan pelatihan dan pengembangan merupakan langkah awal sebelum melakukan proses selanjutnya.

Dengan pelatihan SDM dengan mudah dipahami atau mengerti tentang apa yang ingin dicapaioleh perusahaan. Desler (2009) mengemukakan pengembangan dan pelatihan SDM merupakan proses mengajar karyawan baru untuk memperoleh keahlian dan keterampilan dasar yang mereka butuhkan untuk menjalankan pekerjaan sesuai dengan keinginan perusahaan(Lestari, 2017). Adapun tujuan dari pengembangan dan pelatihan sumber daya manusia adalah untuk mencapai efisiensi kerja karyawan dalam mencapai hasil-hasil kerja yang telah ditetapkan. Perbaikan efisiensi kerja karyawan dapat dicapai dengan meningkatkan :

1. Pelatihan karyawan

Dengan pengadaan pelatihan, karyawan akan mendapatkan kemampuan dan keterampilan yang sesuai dengan keinginan perusahaan

2. Kedisiplinan karyawan

Dengan pemberian kedisiplinan akan menciptakan kondisi kerja yang nyaman dan mendapatkan hasil yang sesuai dengan yang diingin dengan waktu yang efisien.

\section{Strategi Penerapan Sistem Pengendalian Kualitas Bahan Baku}

Strategi penerapan sistem pengendalian kualitas bahan baku menempatkan posisi yang ke empat dimana hal ini faktor transportasi menginginkan sistem pengendalian bahan baku dengan cara penyimpanan bahan baku selama perjalanan(Ali, 2017). Selama ini perjalanan dalam penyimpanan bahan baku tidak maksimal diantaranya:

- Keranjang yang digunakan masih ada kotoran yang terdapat di celah-celah keranjang yang seharusnya disikat dengan sabun dan diklorin agar tidak bau dan tidak terkontaminasi

- Pembawaan bahan baku menggunakan kemasan terbuka seperti keranjang. Hal ini pembawaan rajungan kurang maksimal sehingga dapat terkontaminasi dengan udara luar.

- Meskipun menggunakan keranjang dengan kemasan tertutup seperti tas yang berkantong 2 dibelakang motor yang dibawa dengan motor, namun tas tersebut juga jarang di bersihkan maupun dicuci.

- Untuk pengepakan tidak menggunakan toples yang telah direkomendasikan.

- Tidak menggunakan box yang direkomendasikan dan tidak ada lubang pengeluaran.

\section{KESIMPULAN}

Faktor yang mempengaruhi proses penanganan rajungan yang telah dilakukan dengan perhitungan metode AHP adalah pada transportasi dengan bobot 0,517 atau $51,7 \%$. Strategi pengendalian kualitas pada penanganan rajungan yang tepat yaitu pada pengadaan dan pelatihan SDM, dimana strategi ini merupakan langkah awal yang harus dilakukan untuk memperbaiki pengendalian pada faktor transportsi dengan mengadakan pelatihan karyawan dan kedisiplinan karyawan.

\section{REFERENCES}

Armstrong, M. and H. Murlis. 2003. Reward Manajemen. A Hand Book Of Remuneration Strategy and Practice. Alih bahasa oleh Ramelan. Bhuana Ilmu Populer Gramedia. Jakarta.

Aji. 2010. Media Informasi Solusi Masalah Transportasi. Karawang. http://www.karawanginfo.com/?p=8454 diakses tanggal 11 April 2011.

Dearbon. Grace. 1994. Quality Management. Maylands Avenue Hemel Hempstead. USA.

Feigenbaum, AV. 1992.Kendali Mutu Terpadu. Erlangga. Jakarta

Gaspersz, Vincent. 1998. Manajemen Kualitas Penerapan, Konsep-konsep Kualitas Dalam Manajemen Bisnis Total. PT Gramedia Pustaka Utama. Jakarta. 
Hardjosoedarmo, S. 1996. Total Quality Manajemen. Penerbit Andi. Yogyakarta.

Hariandja, M.T. 2002. Manajemen Sumber Daya Manusia ( Penggandaan Pengembangan, Pengkompensasi, dan Peningkatan Produktivitas Pegawai). PT Gramedia Widiasarana Indonesia. Jakarta.

Hidayati, Feni. 2002. Skripsi Perubahan Mutu daging Setelah Perebusan Sebagai Bahan Baku Produk Pasteurisasi Selama Penyimpanan Suhu Chilling. Universitas IPB. Bogor. http://repository.ipb.ac.id/bitstream/handle/123456789/15601/C02fhi.pdf?sequence=1 diakses tanggal 10 April 2011.

Ali, M. (2017). TEKNIK BUDIDAYA TANAMAN PERKEBUNAN TANAMAN TEMBAKAU.

Lestari, V. N. S. (2017). PENTINGNYA MOTIVASI DALAM UPAYA MENINGKATKAN PRODUKTIVITAS KARYAWAN.

R. Lawrence dan Glueck.1997. Manajemen Strategis dan Kebijakan Perusahaan Edisi Ketiga. Erlangga. Jakarta.

Rahman, Abdul. 2008. Skripsi Penentuan Kriteria Yang Paling Berpengaruh Terhadap Prestasi Kerja Karyawan di CV. Rimba Setosa Sukoharjo. Universitas Muhammadiyah. Surakarta.

Sukmawati, Dkk. 2007. Jurnal Analisis Manajemen Mutu Terpadu di PT Madu Pramuka Cibubur Jakarta. Fakultas Peternakan Universitas Institut Pertanian Bogor . Bogor.

Saaty, T. L. 1993. Pengambilan Keputusan Bagi Para Pemimpin. Edisi Indonesian PT Pustaka BinamanPressindo. Jakarta.

Supriyanto dan Masruchah, I., Manajemen Purchasing: Strategi Pengadaan dan Pengelolaan untuk Perusahaan Manufacturing, Jakarta, Gramedia, 2000.

Muhajird. 2010. Jurnal Pengembangan Industri Hasil Holtikultura Melalui Inovasi Teknologi Proses Minimal. Balai Besar Pengembangan dan Penelitian Pascapanen Pertanian. Bogor. http://pustaka.litbang.deptan.go.id/publikasi/ip033102.pdf diakses tanggal 30 April 2011 